\title{
Geodetic VLBI Analysis at the National Geographic Institute of Spain ${ }^{+}$
}

\author{
Víctor Puente 1,*, Esther Azcue ${ }^{1}$, Susana García-Espada ${ }^{2}$ and Yaiza Gómez-Espada ${ }^{1}$ \\ 1 National Geographic Institute of Spain, General Ibañez de Ibero 3, 28003 Madrid, Spain \\ 2 RAEGE Santa Maria-National Geographic Institute of Spain, Azores, 9580-324, Portugal \\ * Correspondence: vpuente@fomento.es \\ + Presented at the II Congress in Geomatics Engineering, Madrid, Spain, 26-27 June 2019.
}

Published: 12 July 2019

\begin{abstract}
National Geographic Institute of Spain has a strong background concerning technical aspects of geodetic VLBI. As a step forward in this field, a VLBI analysis team has been set up and tests with different software packages have been carried out. In this sense, two VLBI software packages have been used for experimentation activities in order to compare and validate IGE capability to produce accurate and consistent geodetic products, specifically Earth Orientation Parameters, station coordinates and troposphere delays. The purpose of this contribution is to present the results of these analyses, including some tests to use GNSS-based troposphere delay in VLBI processing and the study of gravitational deformation in Yebes radiotelescope.
\end{abstract}

Keywords: VLBI; Earth Orientation Parameters; troposphere; deformation

\section{Introduction}

In the last years, National Geographic Institute of Spain (IGE) has been strongly involved in technical aspects of geodetic VLBI. In this sense, it should be highlighted RAEGE project, for an Atlantic Network of Geodynamical and Space Stations. The aim of this project is setting up a Spanish-Portuguese network of four Geodetic Fundamental Stations, two in Spain (Yebes Observatory and Gran Canaria), and two in Azores Archipelago (Santa María and Flores islands).

National Geographic Institute of Spain is committed to expand its contribution to geodetic VLBI. With this aim, a VLBI analysis team has been set up in order to contribute as much as possible to IVS analysis activities. In this respect, in January 2019 a bid to become potential analysis center was submitted to the IVS Combination Center. In this contribution the VLBI analysis activities that have been carried out so far are presented.

\section{Analysis Tools}

The International VLBI Service for Geodesy and Astrometry [1] is in charge of providing VLBI data and products for the scientific community. Among others, IVS products are terrestrial reference frame (TRF), the international celestial reference frame (ICRF), and Earth Orientation Parameters (EOP). Solutions in SINEX format estimated by individual Analysis Centers (AC) are combined by the IVS Combination Center and later used to produce consolidated products, for instance ITRF14 [2], ICRF3 [3] or IERS EOP 14 C04 series [4].

The selection of the VLBI analysis software package is a choice of the AC. At IGE, two VLBI software packages are currently being used. Software package Where [5] has been used for the reprocessing of 10 years of 24-h VLBI sessions. This is the software package that has been selected as part of the bid submitted in January 2019 to become potential IVS analysis center. Where is written 
in Python and it can be downloaded freely through GitHub. Where is a project of the Norwegian Mapping Authority (NMA).

The other software package that is being used at IGE for research activities is VieVS [6]. This package is coded in MATLAB and it is also accessible through GitHub. VieVS is managed by the Department of Geodesy and Geoinformation of the Technical University of Vienna.

\section{VLBI Processing}

In this section, VLBI analyses carried out so far at IGE are presented. These analyses are further detailed in [7-9].

\subsection{EOP Estimation}

Where software package version 0.16 .3 was used to process R1 and R4 VLBI sessions for the period spanning from 2002 to September 2018. The a priori frames used were ITRF14 and ICRF2 respectively. Station displacements modelling take into account solid tides, ocean loading effect (TPXO.7.2 model), solid and ocean pole tide, atmosphere tides and thermal antenna deformation. Troposphere model used was VMF1. The rest of models used were compliant to IERS Conventions [10].

The set of estimated parameters using a Kalman Filter was the following:

- $\quad$ Station and source coordinates.

- $\quad$ EOP (polar motion and rates, UT1, LOD and celestial pole offsets)

- Station clocks (1 $\mathrm{h}$ interval)

- Zenith troposphere delay (1 h interval) and gradients $(6 \mathrm{~h}$ interval) per station.

EOP differences for the period analysed with Where v0.16.3 were compared to EOP 14 C04 series [4]. The same analysis was performed using EOP estimated by other IVS Analysis Centers such as BKG, GSF, OPA and USN and the IVS combined solution [1]. Differences shown in Figure 1 are shifted in $\mathrm{y}$ axis for each $\mathrm{AC}$ for the sake of visibility.
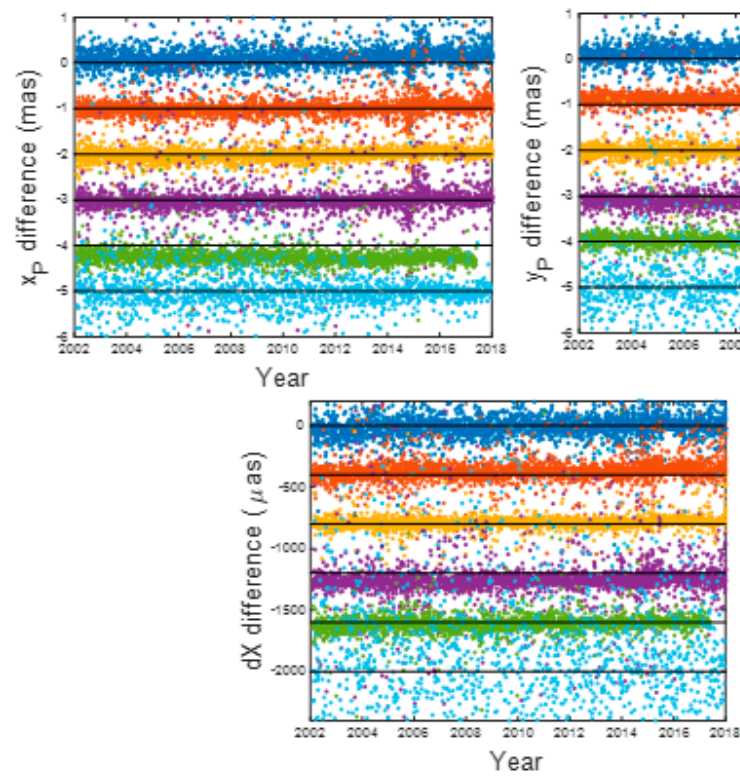
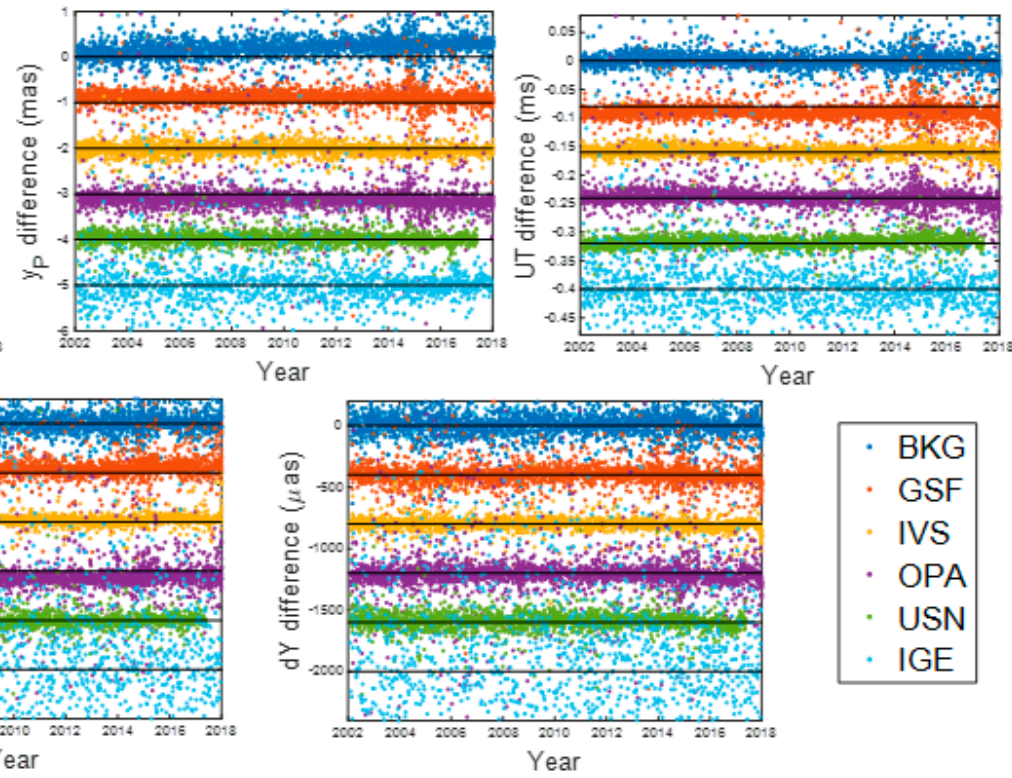

Figure 1. EOP differences with respect to EOP 14 C04 series [4].

The results shown in Figure 1 indicate good agreement for the polar motion components, whereas dUT1 and celestial pole offsets show worse results than other ACs. This is due to the fact that results from other ACs are based on a global solution schema, in which one set of source coordinates is estimated, whereas IGE results estimate source coordinates for each individual session. 


\subsection{Troposhere Estimation}

Zenith Troposphere Delay (ZTD) constitute a common atmosphere parameter in stations where VLBI and GNSS antennas are co-located. It has been compared the VLBI-based ZTD estimated by three individual VLBI AC (IAA, CGS and VIE) and the combined solution (IVS) with respect to GNSS-based ZTD estimated by means of a network solution (CODE) and PPP solution (IGS). This analysis is focused on 12 co-located VLBI antennas (Bd, Hb, Ke, Kk, Ma, Mc, Ny, On, Ts, Wz, Yg, Zc). The period analysed spans from 2013 to 2018. Table 1 reflects a statistical summary of the differences in terms of mean and standard deviation.

Table 1. VLBI-based ZTD differences with respect to GNSS solutions

\begin{tabular}{ccccc}
\hline Solution & CGS & IAA & IVS & VIE \\
\hline VLBI-GNSS CODE $(\mathrm{mm})$ & $0.7 \pm 7.0$ & $-1.2 \pm 7.4$ & $-0.7 \pm 7.2$ & $0.8 \pm 7.9$ \\
VLBI-GNSS IGS (mm) & $0.5 \pm 7.7$ & $-1.3 \pm 8.3$ & $-0.9 \pm 8.0$ & $0.8 \pm 7.9$ \\
\hline
\end{tabular}

Overall results show a good agreement of VLBI-based ZTD with GNSS-based ZTD, regardless the GNSS technique used.

Another analysis on inter-technique troposphere combination carried out at IGE was the usage of GNSS-based ZTD as a priori value in VLBI processing. For this analysis, VieVS 3.1 was modified to read and use GNSS-based troposphere delays as apriori value. The dataset used correspond to CONT17 campaing, in which 14 days of continuous VLBI data is available.

The results in terms of coordinates repeatability are shown in Figure 2. No difference is found between using GNSS-based ZTD as a priori or using an apriori model. Results worsen if GNSS-based ZTDs are used as a priori value and not estimated. Nevertheless, the evolution of the software presented could be used in the frame of VLBI intensive sessions analysis, since GNSS-based gradients improve UT1 estimation [11].

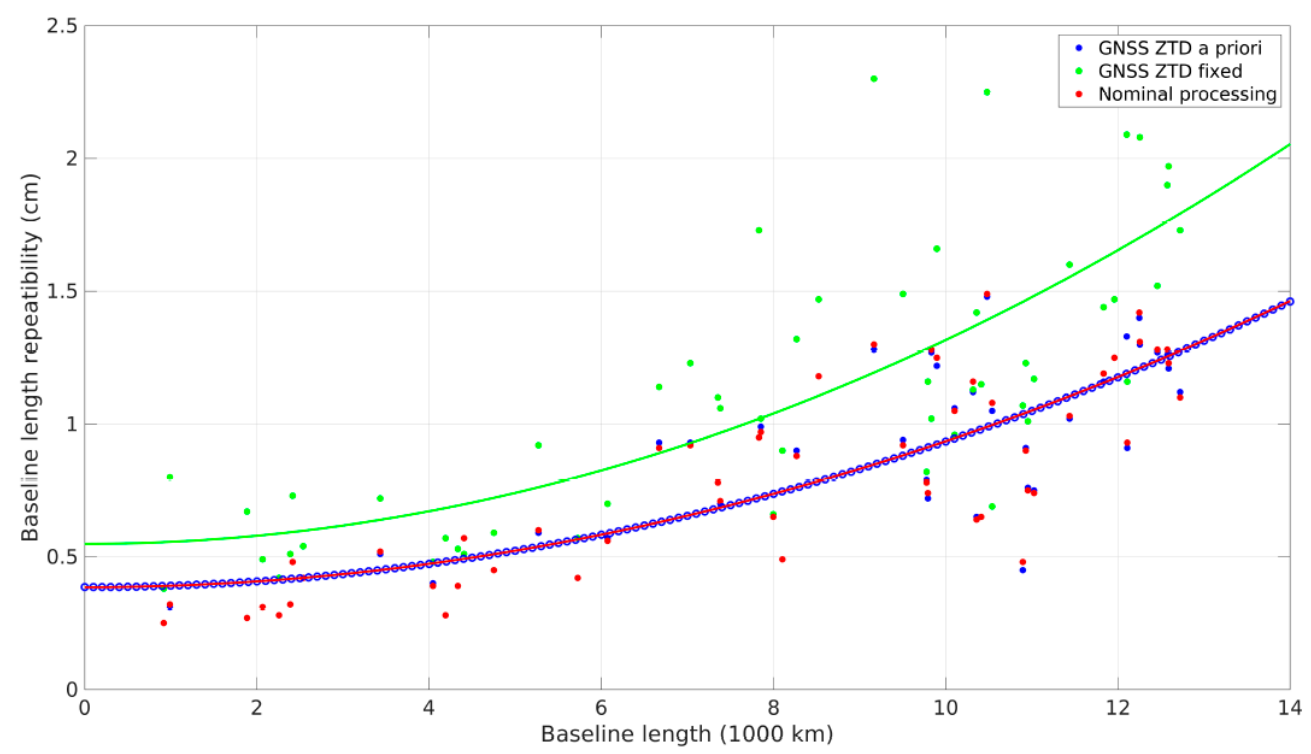

Figure 2. Baseline length repeatabilities in CONT17 campaign under different troposphere estimation configuration.

\subsection{Gravitational Antenna Deformation}

An error source of importance in VLBI processing is gravitational deformation of the antennas. This effect modifies the path length of the radio signal impacting the estimation of the up component of the station coordinates. Due to this, IVS has asked antenna managers to survey antennas using a terrestrial laser scanner or photogrammetry to model gravitational deformation and take into account this information in the analysis. 
IGE is currently planning the survey of $40 \mathrm{~m}$ Yebes antenna using a terrestrial laser scanner. Until this data is available, simulated data has been used to implement MATLAB routines in order to estimate deformation parameters and be ready to produce an antenna deformation model once the survey is done.

\section{Conclusions}

In this contribution, VLBI analysis activities carried out at IGE have been presented. IGE VLBI analysis team is driven to gain more experience on geodetic VLBI analysis and to humbly contribute as much as possible to IVS analysis activities, both in the operational analysis part and in research tasks.

Regarding EOP estimation, the results presented show a similar accuracy than other IVS analysis centers, which indicates IGE team is ready for operational analysis. Concerning GNSS-based troposphere used as a priori value in VLBI analysis of $24 \mathrm{~h}$ sessions, the results do not show any improvement. Nevertheless, the evolution implemented in an existing VLBI software package could be used for the analysis of intensive sessions, where GNSS-based gradients have been proven to be useful.

Funding: This research received no external funding

Conflicts of Interest: The authors declare no conflict of interest

\section{References}

1. Nothnagel, A.; Artz, T.; Behrend, D.; Malkin, Z. International VLBI Service for Geodesy and Astrometry-Delivering high-quality products and embarking on observations of the next generation. J. Geod. 2017, 91, 711-721.

2. Altamimi, Z.; Rebischung, P.; Métivier, L.; Collilieux, X. ITRF14: A new release of the International Terrestrial Reference Frame modeling nonlinear station motions. J. Geophys. 2016, 8, 6109-6131.

3. Charlot, P, Jacobs, C., Gordon, D., Lambert, S., de Witt, A., Böhm, J., Fey, A., Heinkelmann, R., Skurikhina, E., Titov, O., Arias, F., Bolotin, S., Bourda, G., Ma, C., Malkin, Z., Nothnagel, A., Mayer, D., MacMillan, D., Nilsson, T., Gaume, R.. ICRF3, the new realization of the International Celestial Reference Frame. In Proceedings of the 24th Meeting of the European VLBI Group for Geodesy and Astrometry (EVGA), Gran Canaria, Spain, 17-19 March 2019.

4. Bizouard, C.; Lambert, S.; Gattano, C.; Becker, O.; Richard, J.Y. The IERS EOP 14C04 solution for Earth orientation parameters consistent with ITRF 2014. J. Geod. 2019, 93, 621-633.

5. Kirkvik, A.-S.; Hjelle, G.A.; Dähnn, M.; Fausk, I.; Mysen, E. Where-A new software for geodetic analysis. In Proceedings of the 23th EVGA Working Meeting \& 18th IVS Analysis Workshop, Gothenburg, Sweden, 15-19 May 2017.

6. Böhm, J. Böhm, S.; Boisits, J.; Girdiuk, A.; Gruber, J.; Hellerschmied, A.; Krásná, H.; Landskron, D.; Madzak, M.; Mayer, D.; et al. Vienna VLBI and Satellite Software (VieVS) for Geodesy and Astrometry. Publ. Astron. Soc. Pac. 2018, 130, 044503.

7. Azcue, E.; Puente, V.; García-Espada, S.; Gómez-Espada, Y.S.; Valdés, M. VLBI analyses at the National Geographic Institute of Spain. In Proceedings of the 24th Meeting of the European VLBI Group for Geodesy and Astrometry (EVGA), Gran Canaria, Spain, 17-19 March 2019.

8. Puente, V.; Gómez-Espada, Y.; Azcue, E.; García-Espada, S.; Valdés, M. Comparison of troposphere delays from GNSS and VLBI in R1 and R4 sessions. In Proceedings of the 24th Meeting of the European VLBI Group for Geodesy and Astrometry (EVGA), Gran Canaria, Spain, 17-19 March 2019.

9. Prudencio, A.; Azcue, E.; López-Ramasco, J.; García-Espada, S.; Gómez-Espada, Y.; Puente, V.; Valdés, M. First steps in gravitational deformation modelling of the VLBI Yebes radio telescopes. In Proceedings of the 24th Meeting of the European VLBI Group for Geodesy and Astrometry (EVGA), Gran Canaria, Spain, 17-19 March 2019.

10. IERS Conventions. Frankfurt am Main: Verlag des Bundesamts für Kartographie und Geodäsie; IERS Technical Note 36; Petit, G., Luzum, B., Eds.; IERS Convention Centre: Frankfurt am Main, Germany, 2010; ISBN 3-89888-989-6. 
11. Teke, K.; Böhm, J.; Madzak, M.; Kwak, Y.; Steigenberger, P. GNSS zenith delays and gradients in the analysis of VLBI Intensive sessions. Adv. Space Res. 2015, 56, 1667-1676.

(c) (i)

(C) 2019 by the authors. Licensee MDPI, Basel, Switzerland. This article is an open access article distributed under the terms and conditions of the Creative Commons Attribution (CC BY) license (http://creativecommons.org/licenses/by/4.0/). 